\title{
Perioperative management of porphyria: a case report
}

\author{
ROBERT BARONICA ${ }^{1}$, KLAUDIJA PRLIĆ ${ }^{1}$, MARTINA ČALUŠIĆ $C^{\prime}$, MARIJA PLANINIĆ ${ }^{\prime}$, ANTE \\ PENAVIĆ ${ }^{1}$ MARINA KLJAKOVIĆ GAŠPIĆ ${ }^{1}$ KORALJKA BAČIĆ BARONICA ${ }^{2}$ \\ ${ }^{1}$ University Department of Anaesthesiology, Reanimatology and Intensive Care, University Hospital Centre Zagreb, \\ ${ }^{2}$ University Department of Neurology, University Hospital Sveti Duh, Zagreb
}

Corresponding author:

Robert Baronica

University Department of Anaesthesiology, Reanimatology and Intensive Care,

University Hospital Centre Zagreb,

Kišpatićeva 12, 10000 Zagreb, Croatia,

Phone: +38512367858

E-mail: rbaronica@gmail.com

\section{ABSTRACT}

The porphyrias are rare inherited metabolic disorders of the heme biosynthesis pathway. Acute intermittent porphyria is the most common form that may result in acute porphyric crises with abdominal pain, vomiting, hemodynamic disturbances, autonomic dysfunction, pyrexia and neurological deterioration. Provocative factors include hormonal fluctuations, fasting, dehydration, smoking, excessive alcohol or illegal drugs intake and stress from illness or surgery. However, the most frequent triggers are cytochrome P450-inducing drugs, especially in relation to anaesthesia. We report a case of a 63-year-old female with acute intermittent porphyria and severe hemodynamic instability during and after liver resection taken for hepatocellular carcinoma. The procedure was predominantly characterized by unusual hemodynamic instability with refractory hypertension, despite adequate analgesia and depth of anaesthesia. Several different treatments failed to reduce high blood pressure. There is a possibility that some drugs used in the perioperative period caused acute porphyric crises, which was manifested by severe hemodynamic instability. Autonomic neuropathy might have caused labile blood pressure as well. A precise etiology of hemodynamic instability in the presented case is difficult to assess, since other provocative factors like fasting, dehydration and stress from surgery were also present. A careful anaesthetic plan and treatment and postoperative surveillance in the ICU are cornerstones in the management of patients with porphyria subjected to major surgical procedures.
Key words: porphyria, perioperative management, hemodynamic instability

\section{INTRODUCTION}

The porphyrias are rare inherited metabolic disorders of the heme biosynthesis pathway. They are classified according to the deficient enzyme, the hepatic or erythropoietic site of porphyrin production and the possibility of an acute attack. $(1,2)$ Only three autosomal dominant acute hepatic forms (acute intermittent porphyria (AIP), variegate porphyria and hereditary coproporphyria) may result in acute porphyric crises (APC). The most common is AIP with an overall prevalence in Europe of approximately 1 per 20,000 . $(3,4)$ The diagnosis of severe recurrent acute porphyria is associated with an increased risk of hepatocellular carcinoma (HCC). (5) Various factors may provoke APC, including physiological hormonal fluctuations, fasting, dehydration, smoking, excessive alcohol or illegal drugs intake and stress from illness or surgery. (4) However, the most frequent triggers are cytochrome P450-inducing drugs, especially in relation to anaesthesia. (6) According to James and Hift, drugs can be categorized as definitely unsafe to use, probably safe, and controversial. For many drugs there are no available data $(3,4)$ (table 1$)$. The symptoms of APC include severe abdominal pain, vomiting, constipation, acute psychiatric and neurologic manifestations, tachycardia, hypertension, tremors, excessive sweating, urinary retention, cardiac arrhythmias, electrolyte disturbances and acute respiratory paralysis. Perioperative hypovolemia is common, as well as autonomic neuropathy, which may cause labile blood pressure. (3) Inconsistent clinical signs and susceptibility to precipitating factors, even in the same patient, are common and cannot be overemphasized. $(7,8)$

\section{CASE REPORT}

We report a case of a 63-year-old female with a diagnosis of porphyria and an unusual hemodynamic instability during and after liver resection taken for HCC. She was diagnosed with AIP in her student days but has not had any acute attack of the illness for the last 10 years. Periodically, abdominal pain attributable to AIP manifested. In addition to porphyria, hypothyreosis treated with levothyroxine, arterial hypertension treated with angiotensin II antagonist and diuretic were recorded. After the HCC was diagnosed and declared as inoperable, she was treated twice by palliative procedures (transarterial chemoembolization) in another institution. In our hospital decided decision was made that radical liver resection could be undertaken. A preoperative evaluation showed normal biochemical and haematological tests and no acute distress on the physical exam. The patient was premedicated with diazepam, pantoprazole and levothyroxine. In the operating room the list of porphyria safe and unsafe drugs was prepared and placed at a noticeable place (table 1). The induction of general anaesthesia with sufentanil, propofol and vecuronium was uneventful. Central venous, arterial and urinary catheters and a nasogastric tube were inserted. For the maintenance of anaesthesia, sevo- 
flurane combined with oxygen and nitrous oxide (N2O) was used. Successive boluses of sufentanil and vecuronium were administered on a regular basis. The patient's heart rate and blood pressure were continuously and invasively monitored. The entire surgical procedure was characterized by unusual hemodynamic instability, predominantly with refractory hypertension, despite adequate analgesia and depth of anaesthesia. Alternating, short periods of profound hypotension were present as well (figure 1). Several different treatments, including generous boluses of sufentanil and vecuronium, short inhalation boluses of $8 \%$ sevoflurane, the addition of $\mathrm{N} 2 \mathrm{O}$ and boluses of urapidil, propranolol and magnesium sulfate failed to reduce blood pressure. Finally, nitroglycerin was introduced continuously. Two units of red blood cells (RBCs) were administered because of intraoperative blood losses. After the procedure, the patient was admitted to the ICU, where a nitroglycerin infusion was continued throughout the next two days. Moxonidine and doxazosin were added to her usual peroral antihypertensive therapy. She was treated with intravenous glucose and dismissed from the ICU after four days. The second procedure was performed 14 days after the first one, with a similar perioperative management. Again, hemodynamic instability was pronounced, with a hypertensive crisis and tachycardia at the beginning and the end of the procedure (figure 1). The hypertensive crisis was treated with intravenous propranolol and urapidil. The patient was dismissed the next day from the ICU and seven days later from the hospital.

\section{DISCUSSION}

Perioperative management of a porphyric patient is inevitably a challenge, considering that many agents and conditions may induce cytochromes and trigger APC. The porphyrinogenic potential of anaesthetic agents in our patient was difficult to assess with precision, since other provoking factors such as fasting, dehydration and stress from the surgery where also present. (4) During the anaesthesia and in the ICU definitely unsafe drugs were not used. We used drugs that are considered probably safe and drugs whose safety is controversial or not known. There is a possibility that some of them caused APC, which was manifested by pronounced hemodynamic instability. Blood pressure oscillations caused by APC or autonomic neuropathy could be the most distinctive symptoms in the perioperative period. (3) Apart from AIP, the cause of hemodynamic instability in our patient could have been unregulated essential hypertension. The patient's medical history, doses of antihypertensives used before the procedure and preoperative evaluation do not indicate this as a primary cause. It cannot be excluded that hypertension and tachycardia might have been caused by the painful stimuli due to the extensive procedure. However, this is less likely since analgesia and the depth of anaesthesia were maintained at the upper limits. Despite the fact that the liver resection was extensive and prolonged, only two doses of RBCs were applied because of intraoperative blood losses. In the case of severe bleeding, it is possible that hemodynamic disturbance would have been even greater, which might have aggravated APC or caused long-term neurologic complications, hypertension and chronic renal failure. $(6,8,9)$ Considering that renal failure is a quite common complication after major surgery, it is extremely important to monitor renal function in the porphyric patients. Intravenous administration of glucose was initiated since it is known that increased carbohydrates intake may ameliorate APC. $(7,9)$

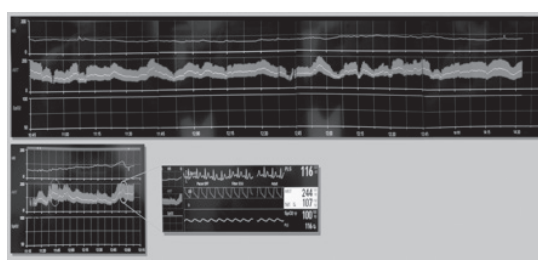

Figure 1. Hemodynamic instability during the first procedure (upper row) and at the beginning and the end of the second procedure (lower row)

\section{CONCLUSION}

Any clinical disorder in the perioperative period displayed by an identified porphyric patient should be considered as the onset of APC. (6) A careful anaesthetic plan, treatment and postoperative surveillance in the ICU are cornerstones in the management of patients with porphyria subjected to major surgical procedures. A detailed preoperative evaluation, early APC diagnosis, drugs selection in the operating theatre and ICU, avoidance of fasting, dehydration, hypovolemia, infection and reduction of surgical stress could prevent acute attacks and long-term complications associated with porphyria.

Table 1. List of porphyria safe and unsafe drugs (adapted from Allman KG, Wilson IH. Oxford handbook of anaesthesia 3rd ed. New York: Oxford University Press;2011.

\begin{tabular}{llll}
\hline & Definitely unsafe & Probably safe & Controversial \\
\hline Induction agents & Barbiturates, Etomidate & Propofol & Ketamine \\
\hline Inhalational agents & Enflurane & Nitrous oxide, & Isoflurane, Sevoflurane \\
\hline Neuromuscular blocking agents & Alcuronium & Suxamethonium, Tubocurarine, & $\begin{array}{l}\text { Pancuronium, Atracurium, } \\
\text { Rocuronium }\end{array}$ \\
\hline
\end{tabular}

Neuromuscular reversing agents

Atropine, Glycopyrronium,




\begin{tabular}{|c|c|c|c|}
\hline Analgesics & Pentazocine & $\begin{array}{l}\text { Alfentanil, Aspirin, Buprenorfine, } \\
\text { Codeine, Fentanyl, Paracetamol, } \\
\text { Pethidine, Morphine, Naloxone }\end{array}$ & $\begin{array}{l}\text { Diclofenac, Ketorolac, Sufen- } \\
\text { tanil }\end{array}$ \\
\hline Local anesthetics & Mepivacaine, Ropivacaine & $\begin{array}{l}\text { Bupivacaine, Prilocaine, Procaina- } \\
\text { mide, Procaine }\end{array}$ & Cocaine, Lidocaine \\
\hline Sedatives & Chlordiazepoxide, Nitrazepam & $\begin{array}{l}\text { Lorazepam, Midazolam, Temaz- } \\
\text { epam, Chlorpromazine }\end{array}$ & Diazepam \\
\hline Antiemetics and $\mathrm{H} 2$ antagonists & Cimetidine, Metoclopramide & Droperidol, Phenotiazines & Ondansetron, Ranitidine \\
\hline CVS drugs & $\begin{array}{l}\text { Hydralazine, Nifedipine, Phenoxy- } \\
\text { benzamine }\end{array}$ & $\begin{array}{l}\text { Adrenaline, } \alpha \text {-agonists, } \beta \text {-agonists, } \\
\beta \text {-blockers, Magnesium, Phentola- } \\
\text { mine, Procainamide }\end{array}$ & $\begin{array}{l}\text { Diltiazem, Diisopyramide, } \\
\text { Nitroprusside, Verapamil }\end{array}$ \\
\hline Others & $\begin{array}{l}\text { Aminophylline, Oral contraceptive } \\
\text { pill, Phenytoin, Sulphonamides }\end{array}$ & & Steroids \\
\hline
\end{tabular}

$\overline{\mathrm{CVS}}$ - cardiovascular system

\section{REFERENCES}

1. Anderson KE, Sassa SS, Bishop DF, Desnick RJ. Disorders of heme biosynthesis: X-linked sideroblastic anemia and the porphyrias. In: Scriver CR, Beaudet AL, Sly WS, Valle, D, Eds. The metabolic basis of inherited disease, 8th edn. New York: McGraw-Hill, 2001.p.453-462.

2. Puy H, Gouya L, Deybach JC. Porphyrias. Lancet 2010;375(9718):924-937.

3. Allman KG, Wilson IH. Oxford handbook of anaesthesia 3rd ed. New York: Oxford University Press;2011.

4. James MFM, Hift RJ. Porphyrias. Br J Anaesth 2000; 85:143-153.

5. Andersson C, Bjersing L, Lithner F. The epidemiology of hepatocellular carcinoma in patients with acute intermittent porphyria. J Intern Med 1996;240(4):195-201.

6. Thadani H, Deacon A, Peters T. Diagnosis and management of porphyria. BMJ 2000;320(7250):1647-1651.

7. Rigal JC, Blanloeil Y. Anaesthesia and porphyria. Minerva Anestesiol 2002;68(5):326-331.

8. Balwani M, Desnick RJ. The porphyrias: advances in diagnosis and treatment. Blood 2012;120(23):4496-4504.

9. Handschin C, Lin J, Rhee J, Peyer AK, Chin S, Wu PH, Meyer UA, Spiegelman BM. Nutritional regulation of hepatic heme biosynthesis and porphyria through PGC-1alpha. Cell 2005;122(4):505-515. 